\title{
A Mobile Semi-Autonomous Robot For Soil Sampling
}

This paper was downloaded from TechRxiv (https://www.techrxiv.org).

\section{LICENSE}

CC BY-NC-SA 4.0

SUBMISSION DATE / POSTED DATE

$19-11-2021 / 23-11-2021$

CITATION

Edulji, Vistasp; Soman, Sumedh; Pradhan, Atharva; Shah, Jay (2021): A Mobile Semi-Autonomous Robot For Soil Sampling. TechRxiv. Preprint. https://doi.org/10.36227/techrxiv.17050970.v1

$\mathrm{DOI}$

10.36227/techrxiv.17050970.v1 


\title{
A Mobile Semi-Autonomous Robot for Soil Sampling
}

\author{
Vistasp Edulji ${ }^{1 \dagger}$, Atharva Pradhan ${ }^{1 \dagger}$, Jay Shah ${ }^{1 \dagger}$, Sumedh \\ Soman ${ }^{1 \dagger}$ and Sangita Bansode ${ }^{{ }^{*}}$ \\ ${ }^{1}$ Department of Mechanical Engineering, K. J. Somaiya College \\ of Engineering, Vidyavihar, Mumbai, 400077, Maharashtra, India.
}

\author{
*Corresponding author(s). E-mail(s): \\ sangeetabansode@somaiya.edu; \\ Contributing authors: vistasp.edulji@somaiya.edu; \\ atharva.mp@somaiya.edu; jps1@somaiya.edu; \\ sumedh.soman@somaiya.edu; \\ $\dagger$ These authors contributed equally to this work.
}

\begin{abstract}
For agrarian economies such as India, the quality of the soil is critical for maximized yield sustainable cultivation. When a large area is utilized, sample testing of soil is essential. The use of a robotic system for sampling is vital for saving time and replacing manual laborious work. This work represents a robotic system that was deployed for soil sample collection. A mechanical soil sampling and storage system based on augers and turntable storage is used in the system. Using a GPS-driven algorithm, the robot navigates autonomously to desired sampling locations. It collects data from the sampling area using sensors connected to an Arduino board. A proof-of-concept demonstrator proved that such a solution can be successfully scaled and deployed, which will aid in more efficient cultivation and sustainable agriculture.
\end{abstract}

Keywords: GPS, soil samples, navigation, robot, mobile robot 


\section{Introduction}

Soil quality testing is an important step in crop cultivation. Such testing aids farmers in making informed decisions regarding the suitability of the soil for different crops. Normally, this process is carried out manually, with samples collected with a shovel, packaged, and transported to laboratories for testing. This process is time-consuming, and laboratories in remote areas are inaccessible, causing the process to be hampered. In case of real-world scenarios, where sampling time available in scarce and vast land tracts are to be covered, soil sampling robots are an appropriate solution, and preliminary analyses can be performed on-site. The robot can also store soil samples if a suitable storage system is provided. The samples can then be transported to laboratories for more advanced tests like soil acidity and so on. In two ways, the proposed design differs from other proposed models in the literature. The first is the use of a semi-autonomous drive system based on GPS sensors and Ultrasound sensors, and the soil delivery system, which collects soil samples with a single Archimedean screw and then stores them in a turntable platform with storage modules. An overview of proposed literature models can be found in the next section. The working of the proposed design has been elaborated in the Methodology section.

\section{Literature Review}

Presently, multiple designs exist for soil sampling robot systems. Lukowska et al. [1] proposed a 6 wheeled design with all-terrain air suspension systems as a platform to mount the sampling equipment, which consists of a custom drill pipe with a flap at the end. The authors mention that the collection systems are still under development. The robot consists of an onboard sensor suite that extracts the data from the soil in real-time. Cao et al. [2] used a cone penetrometer, in addition to a linear actuator and a load cell mounted on a rugged platform, to decide the suitability of the soil for aircraft runway construction. Vaeljaots et al.[3] created an Unmanned Ground Vehicle (UGV) for soil sampling, consisting of a drill to dig and collect the soil, along with a 3 axis electromechanical system to place the samples in sample containers. The software employed calculates the best trajectory between input coordinates, and autonomously navigates to the desired locations. A similar device was also proposed by Olmedo et al. [4]. Mori et al.[5] proposed a soil sampling model for extra-terrestrial applications, by the design of an energy-efficient arm design and soil-tool interaction using Particle Image Velocimetry. Ghaffari et al. [6] proposed a compact autonomous soil sampling robot, which consists of a two-wheeled platform, with a Duplex Cone Penetrometer (DCP) mounted underneath the robot, encased in an aluminium tube. The DCP sampler determines the resistance of the soil which can then be correlated to the California Bearing Ratio (CBR). The robot works on GPS navigation, and the waypoints are marked by flags set in the ground. Huuskonen et al. [7] propose a novel approach for soil sampling, using drones and Augmented Reality (AR) systems. 
Here, the Unmanned Aerial Vehicle (UAV) or drone makes an aerial survey of the entire field and captures images using an RGB camera. The soil quality is then analyzed based on the captured images using dedicated image processing algorithms. Based on these results, management zones are created. A human wearing an AR headset which superimposes these zones onto the field, manually collects soil samples from the targeted areas. Chiodini et al. [8] propose a rover design called Mars Operative Rover of Padova Engineering University Students (MORPHEUS), which is a fully autonomous robot designed for interplanetary exploration and soil sampling. It consists of a 6 wheeled robot, with a sensor suite consisting of GPS IMU, ultrasonic sensors, and other sensors operating in a sensor fusion mode, interfaced to a Jetson TK1 board. The robot uses a simple drill and storage system for soil collection and sampling. The rover is capable of collecting a soil sample of $25 \mathrm{~g}$ from a $15 \mathrm{~cm}$ depth. Fentanes et al. [9] proposed a mobile, autonomous robot for creating spatial maps of soil condition. A Thorvald mobile robot, equipped with GNSS sensors and running a Robot Operating System (ROS) based on Linux is used, with a penetrometer attached, to create the soil condition maps. Instead of random sampling, the system employs Kriging Variance as a reward function to ensure more efficient data collection.

\section{Methodology}

The autonomous robot consists of three different sub-systems. First is the mechanical design consisting of the chassis, drive mechanism and the sample collection system. Second, is the circuitry that performs control, sensing and data collection. Third, we have the controlling algorithm that is directly responsible for the navigation to the intended location. Various simulations were run to validate the proposed soil collection system and the mechanical design.

\subsection{Mechanical Design}

The physical design can be split into three parts. First is the chassis of the robot on which different sensors, motor and turntable are mounted. Second is the selection of the drive mechanism for the robot. Third is the mechanical system to collect and store the soil samples.

\subsubsection{Chassis and Support}

The chassis of the robot is a solid structure made of welded aluminium beams. The chassis' box-like structure allows for even weight distribution and prevents buckling under the weight of the soil samples. Different holes are provided at various locations to allow the mounting of various hardware such as the microcontroller, sensors, and motors. The motor has threads on the shroud that covers the motor shaft, eliminating the need for additional mounting points. Steering is accomplished by running the two motors in opposite directions. The 
front wheels are attached to separate half axles to allow independent movement. This system allows the robot to steer without a conventional steering mechanism.

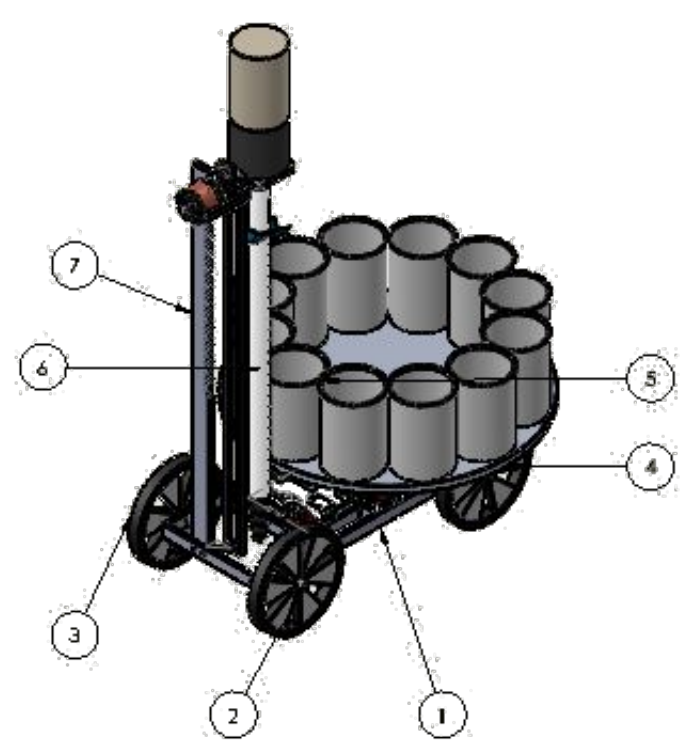

\begin{tabular}{|c|c|}
\hline $\begin{array}{c}\text { Component } \\
\text { Number }\end{array}$ & Component \\
\hline 1 & Chasis \\
\hline 2 & Front semi axle \\
\hline 3 & WhèeI \\
\hline 4 & Tum Table \\
\hline 5 & Sampling Beaker \\
\hline 6 & Auger \\
\hline 7 & Rack and Pinion \\
\hline
\end{tabular}

Fig. 1: CAD model of Autonomous Robot

Accounting for its non-standard bolt holes, the Arduino microcontroller is mounted atop a special plate with stand-offs holding it above the plate. Bolts are used to secure this plate to two beams. The DHT11 temperature and humidity sensor is installed just ahead of the Arduino. The moisture sensor is connected to thee chassis with a slider-crank mechanism actuated using a servo motor. A cage is provided as additional mounting for a stepper motor. The battery is mounted on two beams and is held in place with ratchet straps.

\subsubsection{Drive mechanism}

Many different options were considered while selecting the drive for the robot, including a differential driven by a single motor. However, because it was decided to steer the robot with opposite rotating wheels, a dual-motor drive was required. Despite the availability of various transmissions, all available options either caused power loss or were too large to fit without mechanical interference. The motors were directly coupled to the driving wheels as the available motors could provide the required torque. Powertrain kinematics and traction equations for a four-wheeled vehicle were used to select the motor [10] and the equations were modified to suit the present drivetrain configuration. 


\subsubsection{Sample collection system}

An Archimedean screw powered by a DC motor is used to collect soil samples. This auger drill is encased in a PVC pipe. The screw drills out the soil, which is then transported to the turntable. In a sequential order, the samples are placed in pre-labelled sampling beakers mounted on the turntable.

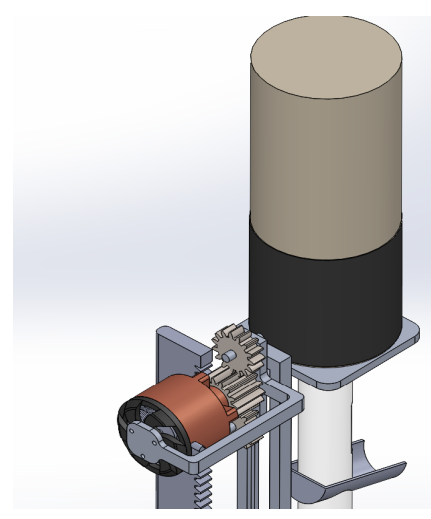

(a) Motors driving the Auger

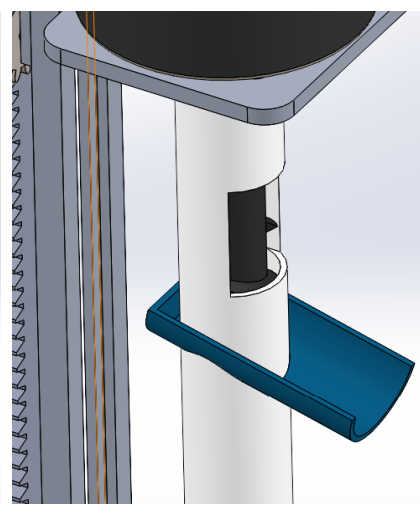

(b) Sleeve for collection of sample

Fig. 2: Auger assembly

As shown in Figure 2a the motor and drill are attached to a slider which constrains movement in all directions except up and down. The vertical movement of the drill is controlled with the use of a smaller DC motor driving a rack and pinion mechanism. This is only used to control the rate of descent as the force required to penetrate the soil is provided by the wedge action of the drill itself. At the top of the sleeve covering the drill is an opening from which the soil can exit after being pushed up by the drill. This opening has a smaller sleeve that guides the incoming soil into the storage container as shown in Figure 2b. The drill runs until all of the soil has been evacuated from the main sleeve, then is retracted to its highest position. The soil is loaded into the sampling beakers on the turntable, which is powered by a stepper motor. This motor can adjust the table's angle to accommodate a newer sample tube.Each of the soil collection tubes are mounted inside a groove on the turntable. This provision secures the samples against any vibrations or any agitations encountered during robot operation. .

\subsection{Circuit Design}

The circuit used for interfacing the of sensors, motors with microcontroller board is shown in Fig.3 
Table 1: Electronic Components used along with its specifications

\begin{tabular}{|l||l|}
\hline Electronic Components & Specifications \\
\hline \hline Arduino UNO[11] & EEPROM: 1KB, Operating Voltage: 7V-12V \\
\hline DC Motor & 500 RPM, 12V \\
\hline L293D Motor Driver[12] & Supply Voltage: 4.5V - 36V \\
\hline Soil Moisture Sensor[13] & $\begin{array}{l}\text { Operating Voltage: } 3.3 \mathrm{~V}-5 \mathrm{~V} \text {, Operating Cur- } \\
\text { rent: } 15 \mathrm{~mA}\end{array}$ \\
\hline $\begin{array}{l}\text { Temperature and Humidity Sensor } \\
\text { DHT11[14] }\end{array}$ & $\begin{array}{l}\text { Operating Voltage: } 3.3 \mathrm{~V}-5 \mathrm{~V} \text {, Temperature } \\
\text { Range: } 0^{\circ} \mathrm{C} \text { to } 50^{\circ} \mathrm{C}, \text { Humidity Range: } 20 \% \text { - } \\
90 \%\end{array}$ \\
\hline Neo 6M GPS Module[15] & $\begin{array}{l}\text { Supply Voltage: } 2.7 \mathrm{~V}-3.6 \mathrm{~V}, \text { Position Accu- } \\
\text { racy: 2.5m }\end{array}$ \\
\hline Ultrasonic Sensor HC-SR04[16] & $\begin{array}{l}\text { Operating Voltage: } 5 \mathrm{~V}, \text { Accuracy: } 3 \mathrm{~mm}, \text { Mea- } \\
\text { suring Distance: } 2 \mathrm{~cm}-450 \mathrm{~cm}\end{array}$ \\
\hline
\end{tabular}

\subsubsection{Micro-controller Board}

Arduino UNO is an open source microcontroller board developed by the Arduino platform. The board is equipped with both digital and analogue, input and output pins which are used to interface different sensors. The microcontroller board has an onboard memory of 1KB EEPROM which is used during the project to save collected data [11]. The Arduino board is powered using $9 \mathrm{~V}$ battery. The microcontroller board was chosen because of its ease of availability and robustness.

\subsubsection{Motor and Driver IC}

Torque and RPM calculations were performed which were used to select the motor. The chosen motor is rated $12 \mathrm{~V}$ and has a 500RPM speed. Two $9 \mathrm{~V}$ batteries in series are used to power the motor. The motor is interfaced with the Arduino board using the L293D motor driver. This driver controls the speed and direction of motor and can run two motors using one IC [12].

\subsubsection{Sensors}

Soil Moisture Sensor module is used for determining the moisture content of the soil. The module consists of a potentiometer, comparator IC and moisture sensor. The sensor has two probes which act as variable resistors and its resistance changes with the water content of soil. The sensor outputs the resistance reading which is then converted into moisture percentage [13].

DHT11 temperature and humidity sensor is used for recording the surrounding temperature. The ambient atmospheric temperature is $10^{\circ} \mathrm{C}-45^{\circ} \mathrm{C}$ which fits well in the range of DHT11 as specified in table 1.

Neo 6M GPS is used to determine the coordinates of current location. This module was chosen because of its accuracy and availability. Also, it can be easily interfaced with Arduino UNO [15]. The navigation algorithm used is explained further. 
The HC-SR04 ultrasonic sensor is used for obstacle detection. The sensor has two ultrasonic transducers of which, one transmits ultrasonic sound pulses, other receives them. If a returning signal is detected, then the duration of high output IO is the time taken for the ultrasonic sound to travel to and from an object. This duration along with velocity of sound is used to calculate a distance. This distance is used to avoid the collision of robot with static and dynamic objects. The theoretical measuring distance is mentioned in the table 1 and its practical measuring distance is $2 \mathrm{~cm}-80 \mathrm{~cm}$ which is sufficient for the safety of the robot.[16]

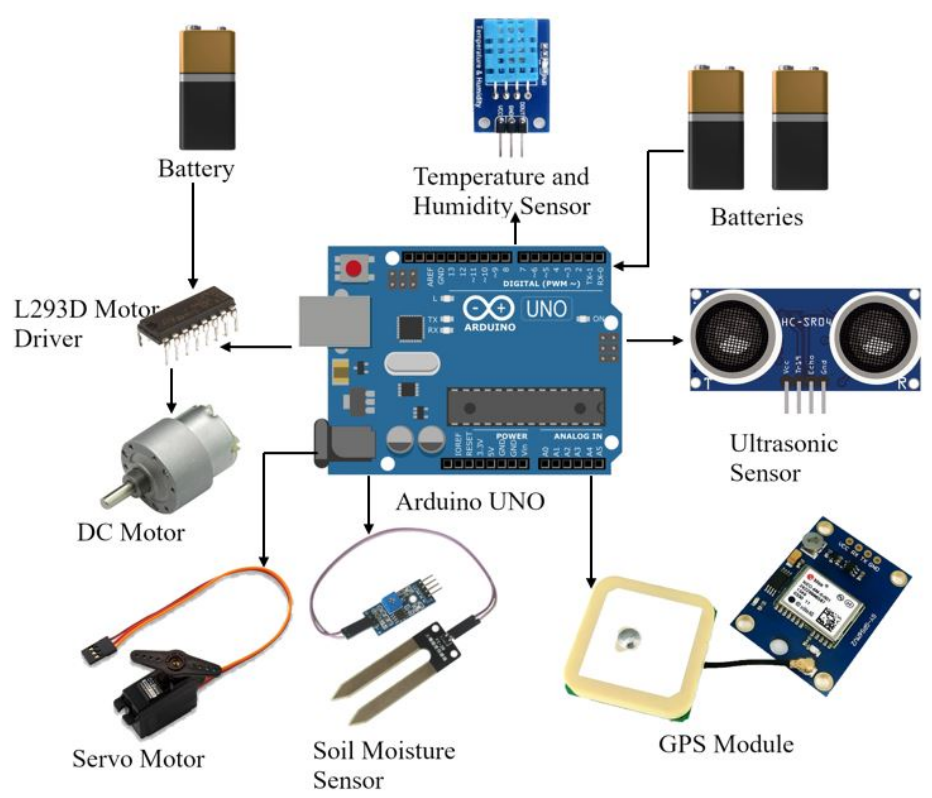

Fig. 3: Component interfacing of the autonomous-Robot

\subsubsection{Working of Robot}

The Arduino microcontroller serves as the robot's brain. It connects to each sensor, including the ultrasonic, moisture, temperature, and humidity sensors, as well as the motor driver. The board and the motors are powered by the batteries. When the appropriate conditions are met, the Arduino board sends a signal to the L293D motor driver, which controls the voltage sent to the motors. Steering is achieved by driving motors on opposite sides of the robot in opposite directions. The board executes its data collection algorithm after reaching the desired destination using the GPS algorithm, collecting data from its sensors and storing it in EEPROM. After collecting the data, the robot moves to the next specified position. The Ultrasonic Sensor measures the distance between the robot and obstacles, and halts if any obstacle is detected in its immediate 
vicinity. The moisture data of the intended location is collected by the servooperated soil moisture sensor. The temperature and humidity of the sampling location are collected by the DHT11 sensor.

\subsection{Control Algorithms}

As discussed in this section, the navigation algorithm serves as the foundation of the project and assists the robot in completing the navigation task. The Algorithm makes use of basic geometry concepts, an Arduino Microcontroller. The data from the module is obtained in the standard from National Marine Electronics Association (NMEA). This data is parsed using TinyGPS++ library. The algorithm assumes that the Navigation takes place on flat land with no obstacles in the robot's path. The defined algorithm has a Time Complexity of $\mathrm{O}(\mathrm{n})$, where $\mathrm{n}$ is the number of targets provided to the robot. In the case of multiple targets, a linear data structure like array can be used with a nested condition to store the values of various targets.

The GPS Module and hex file is provided by 'TheEngineeringProjects.com'. Besides Arduino and GPS Module, a virtual terminal was used for visualization of the data exchanged between GPS Module and Arduino. The pins of Arduino, GPS Module and Virtual Terminal responsible for transmission and receiving the data are connected to develop the simple circuit. The circuit is developed and simulated using the Proteus Software.

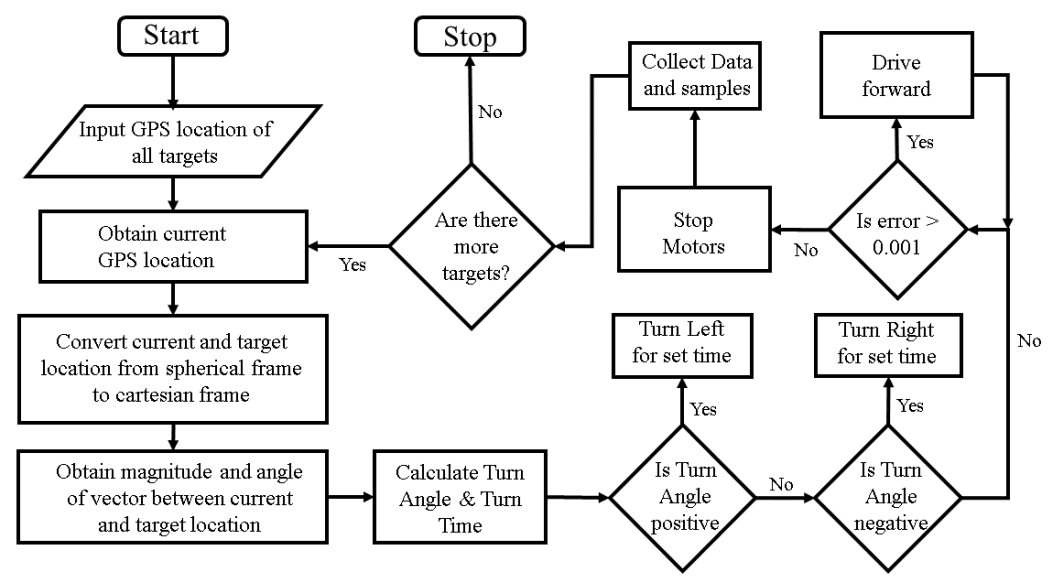

Fig. 4: Navigation Algorithm in standard flowchart format

The program is initially fed the values for the target locations' longitudes and latitudes. The current values of longitude and latitude are obtained from the GPS Module after the program is initiated. Because latitude and longitude values locate a point on a sphere, they must be converted into Cartesian 
co-ordinates before use. This was accomplished by employing the standard conversion formula shown below as given in [17].

Any point $\mathrm{P}$ on a sphere with latitude $\phi$ and longitude $\lambda$ is given by,

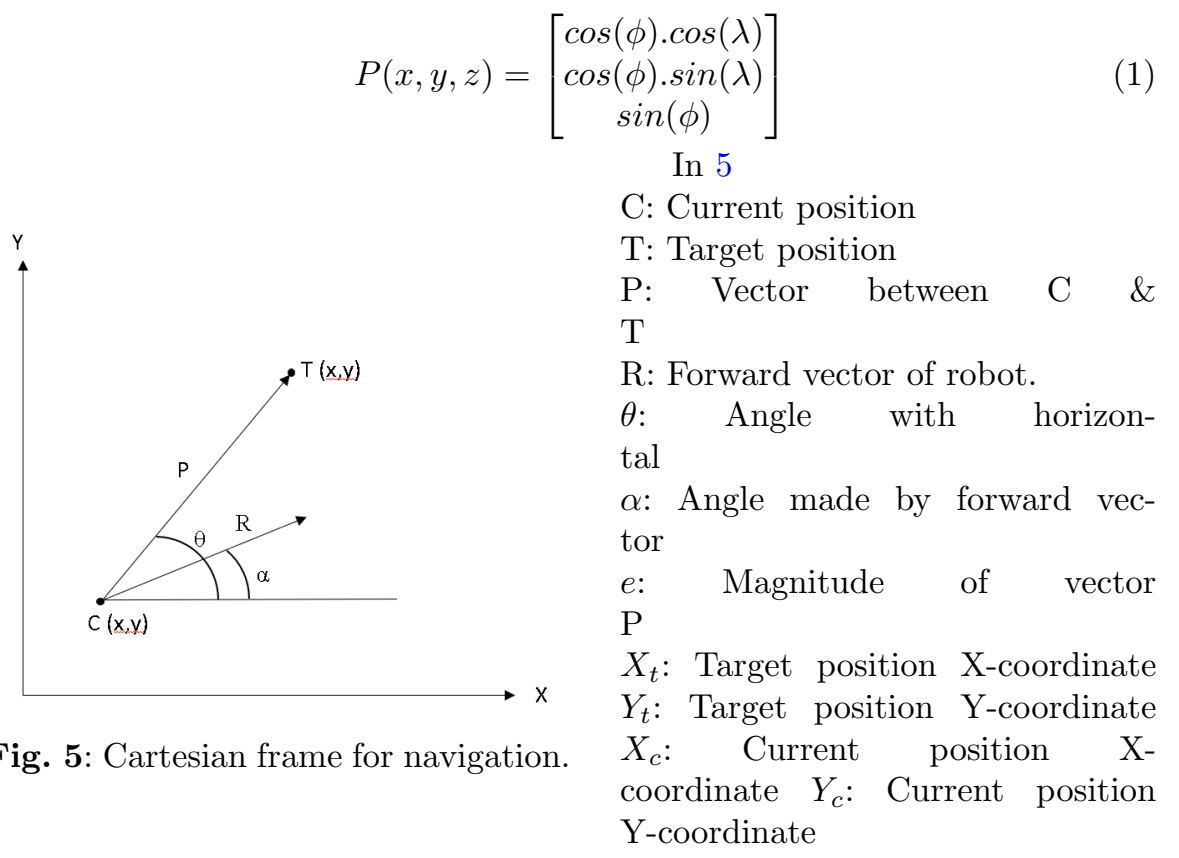

The algorithm calculates the value of theta using,

$$
\theta=\tan ^{-1}\left(\frac{Y_{t}-Y_{c}}{X_{t}-X_{c}}\right)
$$

After calculation of $\theta$, the angle of turn is computed by subtracting the current angle from theta. During the start of the program the robot is aligned east and the current angle is set to zero.

Let, $\alpha$ be the angle made by the robot prior to performing turn. Then, the angle to be turned is given by,

$$
A=\theta-\alpha
$$

By using the equations formulated by Pasztror [18], the revolutions of the wheel required to complete the turn are estimated. By dividing the number of revolutions by the rotational speed of the motor, the time for which the motors need to be actuated can be found out. The direction of the turn is indicated by the sign of the angle $A$.

After executing the turn successfully, the value for $e$ using the distance formula between two points is calculated using the following equation 


$$
e=\sqrt{\left(Y_{d}-Y_{p}\right)^{2}+\left(X_{d}-X_{p}\right)^{2}}
$$

If the error term $e$ exceeds threshold values, the motors are sent a signal to start moving in the forward direction. The robot checks for obstacles in its path after a brief delay. If the path is clear, the robot rechecks the error value to see if the distance moved is sufficient. If the error term is less than the threshold value, the motors are stopped and data collection begins.

\subsection{Simulations}

\subsubsection{Finite Element Analysis}

To check the design of the robot, multiple simulations were carried out. The chassis was subjected to a FEA analysis to determine its suitability to handle the load imposed by the electronics and the other sub assemblies. The simulation was performed using ANSYS Mechanical 2021 R1. The geometry was imported and meshed using tetrahedral elements. Supports were added at the wheel mounting points, and loading applied on the turntable mounting points, as well as the motor mounts and mounting areas for the auger assembly. Additional loads were added to account for the electronics and the batteries. The loads applied on the chassis were twice the actual load, to test the suitability of the design to handle extreme stresses. The total deformation and the Von Mises stress in the chassis were obtained as the output, as can be seen in Figure $6 \mathrm{a}$ and Figure $6 \mathrm{~b}$. It can be clearly observed that the chassis is very well suited for the given loads, with the deformation being less than $0.004 \mathrm{~mm}$ and the maximum stress induced being less than $3 \mathrm{MPa}$, far lesser than the yield stress of Aluminium.

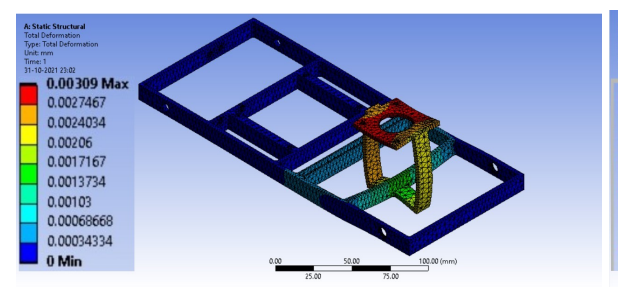

(a) Total Deformation plot (mm)

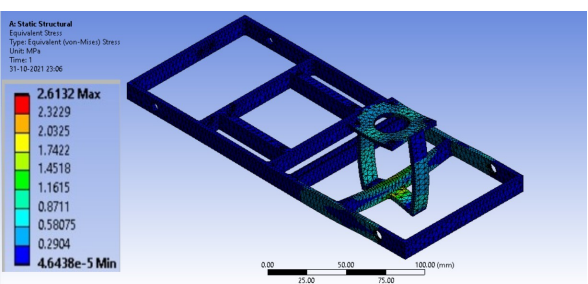

(b) Von Mises stress plot (MPa)

Fig. 6: FEA of Chassis

\subsubsection{Multi-Body Analysis}

A multi-body analysis of the auger assembly was also performed using MATLAB and Simulink, to simulate the mechanism of the assembly, and it was found that the design was completely suitable for the required purpose. Simulations of the Arduino based circuit, that allows the robot to navigate 
semi-autonomously were performed on Proteus, and the circuit was able to successfully execute the task of navigation with target GPS coordinates set as input.

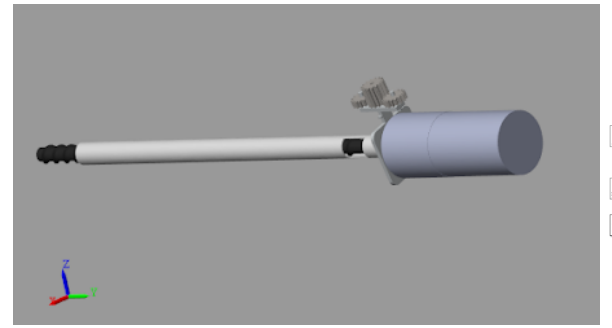

(a) Multi Body Analysis of Auger

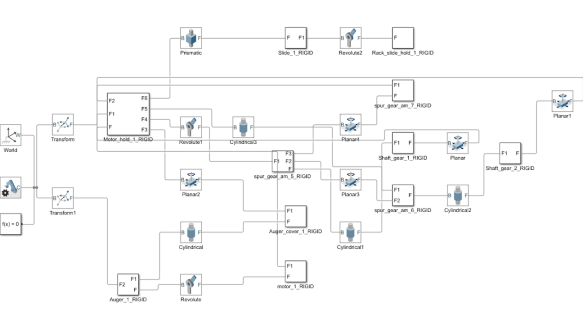

(b) Block diagram for MBD

Fig. 7: Multi-body Analysis of design

\section{Results \& Discussions}

The various sensors those were used in the project were tested for accuracy and reliability. The data collected and studied is presented in the following section.

\subsection{GPS Data Collection and Validation}

The soil in the field needs to be divided into different zones from which the soil must to be collected. These collection points form the input to the robot, which takes the longitudes and latitudes of the collection points and uses them to traverse the field. To check the accuracy of the robot, coordinates of different places in a certain locality were collected. Table 2 below depicts these findings and the error observed. Locations where large errors were observed in the coordinates returned by the sensor were due to the signal being obstructed by buildings in the immediate vicinity.

Table 2: GPS Data

\begin{tabular}{|c|c|c|c|c|c|}
\hline \multirow{2}{*}{ Points } & \multicolumn{2}{|c|}{ GPS Location from Sensor } & \multicolumn{2}{c|}{ Actual GPS Co-ordinates } & Distance \\
& Latitude & Longitude & Latitude & Longitude & error $(\mathrm{m})$ \\
\hline $\mathrm{A}$ & $19^{\circ} 04^{\prime} 23.17^{\prime \prime} \mathrm{N}$ & $72^{\circ} 53^{\prime} 58.11^{\prime \prime} \mathrm{E}$ & $19^{\circ} 04^{\prime} 23.20^{\prime \prime} \mathrm{N}$ & $72^{\circ} 53^{\prime} 58.30^{\prime \prime} \mathrm{E}$ & 5.62 \\
\hline $\mathrm{B}$ & $19^{\circ} 04^{\prime} 22.54^{\prime \prime} \mathrm{N}$ & $72^{\circ} 53^{\prime} 56.74^{\prime \prime} \mathrm{E}$ & $19^{\circ} 04^{\prime} 22.50^{\prime \prime} \mathrm{N}$ & $72^{\circ} 53^{\prime} 56.70^{\prime \prime} \mathrm{E}$ & 1.70 \\
\hline $\mathrm{C}$ & $19^{\circ} 04^{\prime} 22.86^{\prime \prime} \mathrm{N}$ & $72^{\circ} 53^{\prime} 57.61^{\prime \prime} \mathrm{E}$ & $19^{\circ} 04^{\prime} 22.80^{\prime \prime} \mathrm{N}$ & $72^{\circ} 53^{\prime} 57.60^{\prime \prime} \mathrm{E}$ & 1.88 \\
\hline $\mathrm{D}$ & $19^{\circ} 04^{\prime} 21.35^{\prime \prime} \mathrm{N}$ & $72^{\circ} 53^{\prime} 58.51^{\prime \prime} \mathrm{E}$ & $19^{\circ} 04^{\prime} 21.40^{\prime \prime} \mathrm{N}$ & $72^{\circ} 53^{\prime} 58.50^{\prime \prime} \mathrm{E}$ & 1.57 \\
\hline $\mathrm{E}$ & $19^{\circ} 04^{\prime} 20.82^{\prime \prime} \mathrm{N}$ & $72^{\circ} 54^{\prime} 00.94^{\prime \prime} \mathrm{E}$ & $1^{\circ} 04^{\prime} 21.22^{\prime \prime} \mathrm{N}$ & $72^{\circ} 54^{\prime} 00.97^{\prime \prime} \mathrm{E}$ & 12.27 \\
\hline
\end{tabular}




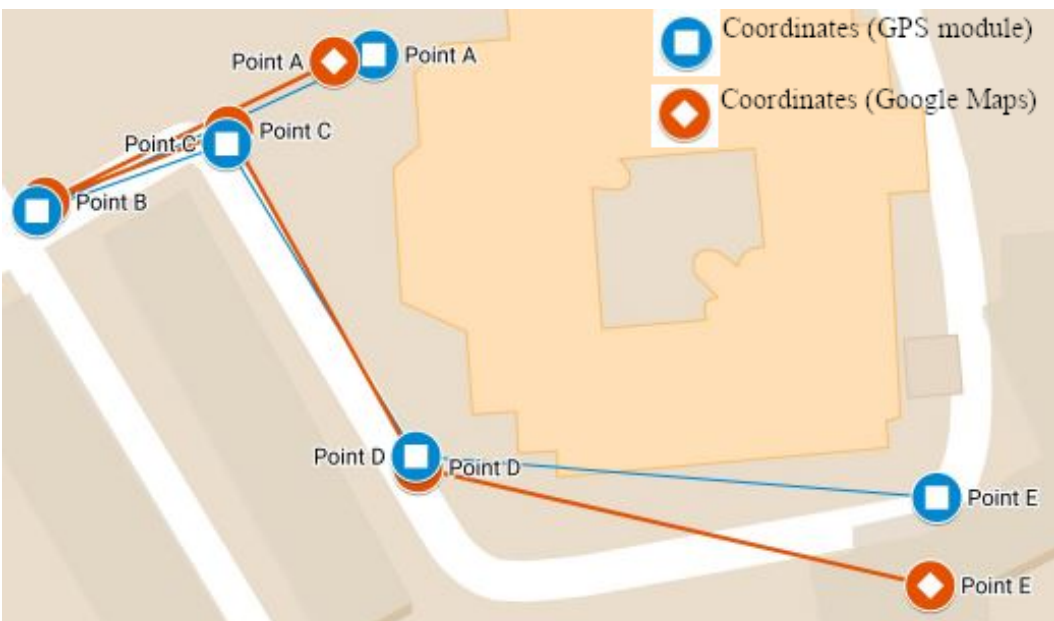

Fig. 8: Comparison of GPS Co-ordinates from GPS module with Google Maps

From the data collected, the error is marginal at points B,C and D, whereas at points $\mathrm{A}$ and $\mathrm{E}$ it was significantly higher. The high error in the signal can be attributed to the proximity of these points to buildings, whose concrete structures interfere with the GPS signal. As points B,C and D were located in relatively open spaces, it can be safely said that, in a field, the GPS sensor will be accurate enough for navigational purposes.

\subsection{Distance measurement via Ultrasonic Sensor}

In order to detect obstacles in the path of the robot an Ultrasonic Sensor is employed. As per present observations the error in sensor output is directly proportional to the distance. Table 3 indicates the sensed distance against the actual distance from an object

Table 3: Distance Sensor Data.

\begin{tabular}{|c|c|}
\hline Sensor Reading $(\mathrm{cm})$ & Measured Distance $(\mathrm{cm})$ \\
\hline 2 & 2 \\
\hline 19 & 20 \\
\hline 28 & 30 \\
\hline 46 & 49 \\
\hline 77 & 82 \\
\hline
\end{tabular}

The percentage error has a maximum value of $6.7 \%$ and reduces to less than $2 \%$ at distances under $10 \mathrm{~cm}$ allowing for the robot to come to a halt safely when necessary. Furthermore, as error is positive, there is no chance of the robot overshooting the stopping point. 


\subsection{Soil Moisture Sensor Data}

Soil moisture is a critical factor in controlling the extent to which plants can utilize the sunlight for photosynthesis and is very important for agriculture. [19]. Hence, the sensor selected was tested by adding different quantities of water in the soil.It can be observed from table 4 that the soil moisture percentage indicated by the sensor increased as more water was added to the soil which reinforces the appropriate working of the sensor.

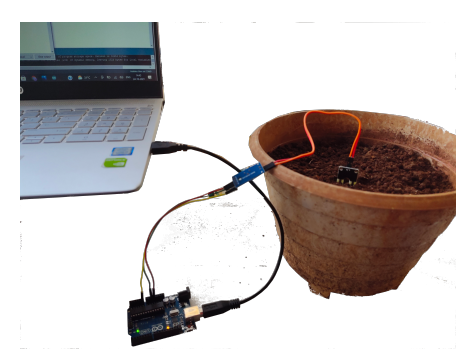

Fig. 9: Testing of Soil Moisture Sensor

\begin{tabular}{|c|c|}
\hline $\begin{array}{c}\text { Water added } \\
\text { to soil }(\mathrm{ml})\end{array}$ & $\begin{array}{c}\text { Measured moisture } \\
\text { percentage }\end{array}$ \\
\hline 0 & 7.645 \\
\hline 100 & 61.316 \\
\hline 125 & 69.395 \\
\hline 150 & 70.634 \\
\hline 175 & 69.677 \\
\hline 200 & 70.89 \\
\hline 300 & 80.574 \\
\hline
\end{tabular}

Table 4: Soil Moisture Sensor Values

\subsection{Temperature and Humidity Sensor Data}

In order to accurately determine soil parameters, it is necessary to be aware of the ambient conditions at which the sample data was collected. Since variations in temperature and humidity of air can affect soil parameters it is important to include them in the system. The sensors selected for the project were tested for their accuracy by collecting data over a period of 12 hours and comparing with publicly available weather data via Google. The findings have been tabulated below.

Table 5: Temperature and humidity sensor

\begin{tabular}{|l|c|c|c|c|}
\hline \multirow{2}{*}{ Date, Time } & \multicolumn{2}{|c|}{ Sensor Data } & \multicolumn{2}{c|}{ Weather Data } \\
\cline { 2 - 5 } & Temperature $\left({ }^{\circ} \mathrm{C}\right)$ & Humidity $(\%)$ & Temperature $\left({ }^{\circ} \mathrm{C}\right)$ & Humidity (\%) \\
\hline $\begin{array}{l}\text { 18th Oct, 2021, } \\
\text { 12:12 IST }\end{array}$ & 32 & 61 & 32 & 62 \\
\hline $\begin{array}{l}\text { 18th Oct, 2021, } \\
\text { 15:12 IST }\end{array}$ & 31 & 59 & 32 & 58 \\
\hline $\begin{array}{l}\text { 18th Oct 2021, } \\
\text { 18:12 IST }\end{array}$ & 31 & 65 & 30 & 66 \\
\hline $\begin{array}{l}\text { 18th Oct, 2021, } \\
21: 12 \text { IST }\end{array}$ & 30 & 71 & 28.5 & 74 \\
\hline $\begin{array}{l}\text { 19th Oct, 2021, } \\
\text { 00:12 IST }\end{array}$ & 29 & 75 & 28 & 77 \\
\hline
\end{tabular}




\section{Conclusion}

Thus, a solution for automated soil sampling utilizing a mobile, semiautonomous robot was proposed. The salient points that emerged from this study are as follows

1. The mechanical design of the robot chassis was validated using Finite Element Analysis. Soil sample collection mechanisms was checked using multi-body simulation facilities available in Simulink.

2. The data collected by the Temperature \& Humidity and Soil Moisture sensors allow for proper analysis of the conditions to which the soil is exposed. The sensors exhibited remarkable accuracy ( $2 \%$ average error) in sensing the temperature and humidity values of the environment they were subjected.

3. The analysis of the GPS sensor data proves that it is suitable for the specified use case of sampling in an open field, with an average distance error of $4.6 \mathrm{~m}$. The Ultrasonic sensor allows for the robot to come to a safe stop should there be a dynamic or static obstacle, with sensor readings displaying an average error of $4.8 \%$. The semi-autonomous algorithm was simulated on Proteus and was found to be perfectly suited for the current application.

4. Although the Proof-of-Concept (PoC) built had very limited functionality, owing to the pandemic situation, upon analyzing the performance and data gathering capabilities of the $\mathrm{PoC}$, it is evident that the fully functioning prototype will prove to be very effective in its designated task of soil sampling and analysis, and will also prove to be cost effective.

\section{Future Scope}

Further augmentations and improvements to the robot include the implementation of a proper suspension system and driving mechanism to traverse rougher terrain. This could further be augmented with the use of a traction control system. The soil sampling unit proposed is limited in its storage capacity by the turntable arrangement for soil collection. The current navigation algorithm, although capable of navigation is limited by the steering capabilities of the robot. A proper steering mechanism with a closed-loop feedback system will endow the robot with better navigating capabilities. Additional sensors mounted to the robot can be used to monitor crops in real-time and can be used to decide whether to spray pesticides or not.

\section{References}

[1] Łukowska, A., Tomaszuk, P., Dzierżek, K., Magnuszewski, Ł.: Soil sampling mobile platform for agriculture 4.0. In: 2019 20th International Carpathian Control Conference (ICCC), pp. 1-4 (2019). IEEE

[2] Cao, P.M., Hall, E.L., Zhang, E.: Soil sampling sensor system on a mobile 
robot. In: Intelligent Robots and Computer Vision XXI: Algorithms, Techniques, and Active Vision, vol. 5267, pp. 304-310 (2003). International Society for Optics and Photonics

[3] Vaeljaots, E., Lehiste, H., Kiik, M., Leemet, T., et al.: Soil sampling automation case-study using unmanned ground vehicle. Eng. Rural Dev 17, 982-987 (2018)

[4] Olmedo, N.A., Barczyk, M., Zhang, H., Wilson, W., Lipsett, M.G.: A ugv-based modular robotic manipulator for soil sampling and terramechanics investigations. Journal of Unmanned Vehicle Systems 8(4), 364-381 (2020)

[5] Mori, D., Ishigami, G.: Excavation model of soil sampling device based on particle image velocimetry. Journal of Terramechanics 62, 19-29 (2015)

[6] Ghaffari, M., Cao, P., Hall, E.: Autonomous techniques for soil sampling in hazardous fields. In: International Conference on Human Impacts on Soil Quality Attributes in Arid and Semiarid Regions, pp. 159-163 (2005)

[7] Huuskonen, J., Oksanen, T.: Soil sampling with drones and augmented reality in precision agriculture. Computers and electronics in agriculture 154, 25-35 (2018)

[8] Chiodini, S., Carron, A., Pertile, M., Todescato, M., Bertolutti, E., Bilato, A., Boscardin, A., Corrà, G., Correnti, A., Dalla Vecchia, R., et al.: Morpheus: A field robotics testbed for soil sampling and autonomous navigation. In: Proc. 1st Symposium on Space Educational Activities (2015)

[9] Fentanes, J.P., Gould, I., Duckett, T., Pearson, S., Cielniak, G.: 3-d soil compaction mapping through kriging-based exploration with a mobile robot. IEEE Robotics and Automation Letters 3(4), 3066-3072 (2018)

[10] Rattan, S.S.: Theory of Machines. Tata McGraw-Hill Education, ??? (2014)

[11] Arduino - Home. https://www.arduino.cc/. (Accessed on 10/31/2021)

[12] L293D Motor Driver IC Pinout, Equivalent ICs, Features and Datasheet. https://components101.com/ics/1293d-pinout-features-datasheet. (Accessed on 11/15/2021)

[13] Soil Moisture Sensor Module Pinout, Features, Specs \& Circuit. https:// components101.com/modules/soil-moisture-sensor-module. (Accessed on $11 / 15 / 2021)$ 
[14] DHT11 Sensor Pinout, Features, Equivalents \& Datasheet. https: //components101.com/sensors/dht11-temperature-sensor. (Accessed on $11 / 15 / 2021)$

[15] NEO-6_DataSheet_(GPS.G6-HW-09005).pdf. https://www.u-blox. com/sites/default/files/products/documents/NEO-6_DataSheet_(GPS. G6-HW-09005).pdf. (Accessed on 11/15/2021)

[16] HC-SR04 Ultrasonic Sensor Working, Pinout, Features \& Datasheet. https://components101.com/sensors/ ultrasonic-sensor-working-pinout-datasheet. (Accessed on 11/15/2021)

[17] Li, C., Qian, Y., Lu, M., Feng, Z.: The design and implement of gps software simulation platform. In: 2008 Asia Simulation Conference - 7th International Conference on System Simulation and Scientific Computing, pp. 186-191 (2008). https://doi.org/10.1109/ASC-ICSC.2008.4675353

[18] Pasztor, A.: Gathering simulation of real robot swarm. Technical Gazette 21, 1073-1080 (2014)

[19] Henderson-Sellers, A.: Soil moisture: A critical focus for global change studies. Global and Planetary Change 13(1-4), 3-9 (1996) 